\title{
Sinemada Mimarlık
}

\author{
Ali Aydin ${ }^{1}$ \\ ORCID: 0000-0002-5063-1105
}

Hikmet Temel Akarsu, Nevnihal Erdoğan ve Türkiz Özbursalı

Sinemada Mimarlik İstanbul, 2020, Yem Yayınları

Hikmet Temel Akarsu, Nevnihal Erdoğan ve Türkiz Özbursalı tarafından yayına hazırlanan "Sinemada Mimarlık" kitabı 2020 yılında Yem Yayıncılık tarafından basıldı. Kitap çoğunluğu mimar olan, alanında uzman, farklı disiplinlerden 40 yazarın 68 tane filmi ele aldıkları inceleme yazılarından oluşan kolektif bir yayın niteliği taşımaktadır. Kitabın bu çok sesli yapısı farklı temalardaki kült filmlerle de birleşince ortaya genel okuyucuya hitap eden bir eser çımaktadır. Kitabın editoryal kurgusu kendine sorun edindiği mesele ile de koşut bir ilişki içerisindedir. Günümüzde yeteri seviyeye ulaşmasa da artık çoğu disiplinin kendi alanında sınırlı kalması gerektiği düşüncesinin ne büyük kayıplara ve eksikliklere yol açtığı ortaya çıkmıştır. Bu disiplinler içerisinde ise izini en belirgin olarak hissettiğimiz hiç kuşkusuz mimarlık sanatıdır. Mimarlık sanatı diğer sanatlardan farklı olarak, Vitruvius'tan beri imalat "Fabrica" ve kuramsal boyut "Ratiocinatio" olmak üzere iki farklı rasyonaliteyi barındırmaktadır. (Picon, 2019, s.22) Mimarlığı diğer sanatlardan ayıran bu ikircikli yapısı ister istemez onu disiplinlerarası bir alana itmektedir. Sözün kısası mimarlık sanatı disiplinlerarası bir bakışı zorunlu kılmaktadır. Bu bağlamdan bakıldığında "Sinemada Mimarlık" kitabı hem yazar kadrosu hem de konuyu ele alış biçimiyle bu yetkinliği hedeflemektedir.

\footnotetext{
${ }^{1}$ Kocaeli Üniversitesi Fen Bilimleri Enstitüsü

id ealkent@ Kent Araştırmaları Dergisi (Journal of Urban Studies)

http://idealkentdergisi.com

Geliş TarihiReceived Date: 06.03.2021 Kabul Tarihi Accepted Date: 27.04.2021
} 


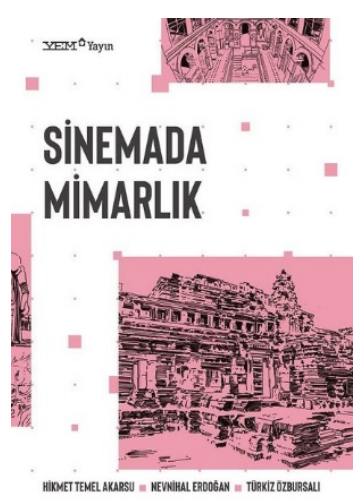

Şekil 1. "Sinemada Mimarlık” Kitap Kapak Tasarımı(Akarsu, H. T. ve Erdoğan, N. ve Özbursalı. T. (Der.). (2020). Sinemada Mimarlı. İstanbul, Yem Yayın.)

Sinema ve mimarlık ilişkisinin başladığı tarihi tam olarak kestirebilmek güçtür fakat insanı ve dünyasını ele alış biçimleri arasında benzerlikler kurabilmek mümkündür. Söz gelimi iki sanat dalı da ortaya koyduğu gerçekliğin sahiciliğini, seyirci ya da kullanıcı ile uzlaşmaya dayalı bir anlaşma üzerine kurar. İki sanat dalı da belirli bir kabul sınırından sonra başlamaktadır. Bu noktadan sonra ise kullandıkları yöntem ve yahut ele aldıkları şeyleri işleme biçimleri olarak tanımlayabileceğimiz üslupsal farklılıklar ortaya çıkmaktadır. Bu farklılığı ise kullandıkları kavramlara yaklaşımı üzerinden gerçekleştirmektedirler. Örneğin mekan ikisinde de başat bir rol izlerken; sinemada anlatının destekleyicisi ya da tezahürü bir konumundayken mimarlıkta anlatının kendisi rolünü üstlenmektedir. Bu farklılıklar göz önünde bulundurularak sinema ve mimarlığa yaklaşmak, günümüzde yaşanan birçok sıkıntıları farklı perspektiflerden görmemizi kolaylaştıracak ve alışılagelenin dışında kazanımlar sağlayacaktır.

Kitap, seçilen filmlerin konuları ve mimari ile kurduğu ilişkiler bağlamında 10 ayrı başlıktan oluşmaktadır. Bu başlıklara bakıldığında kent, zaman-mekan, ekoloji gibi mimarlık disiplininden aşina olduğumuz bir takım mefhumlara rastlasak bile bazı başlıkların mimarlıkla olan ilişkisini ilk bakışta kestirebilmek güçtür. Fantezi, bilimkurgu ve distopya gibi başlıklar altında incelenen bu filmler, mimarlıkla doğrudan olmasa bile dolaylı yoldan ilişki kurmaktadır. Disipliner düşünme alışkanlığını sarsacak ve hayal gücünü besleyecek bu filmler, tasarımsal sürecin etrafında şekillenen mimarlığı besleme potansiyeli barındırmaktadır.

"Mimarlı̆̆a İlham Veren Filmler" başlığı adı altında, mimar ve mimarlık pratiğini konu edinen filmler incelenmiştir. Söz gelimi, "Mimar Babam", "Bir Oğulun Yolculuğu”, "Frank O. Gehry'nin Eskizleri" ve "Mimar" gibi 
filmler mimarı ve yaşantısını konu edinirken, "Ev Yaşamı", "Oyun Zamanı" ve "Amcam" gibi filmler ise mimarlık pratiğini farklı perspektiflerden ele alarak döneminden izler taşımaktadır. Bu ve benzeri türden filmlerin incelendiği bölüm ile birlikte, çoğu kez günümüzden bakmak zorunda kaldığımız mimari olgulara, döneminin gözünden bakabilme imkanı sağlanmakta ve çoğu kez sorgusuz kabul gören geçmiş hakkında eleştirel bir bakış oluşturmaya katkı sağlamaktadır. Masiero'nun “yirminci asrın ortalarından itibaren çoğu sanatçı eserini projelendirerek ve gerçekleşmesini sağlayarak mimarın prosedürlerini benimsedi" ş̧eklinde bahsettiği; mimarlık pratiği ile sinema arasındaki uygulamaya yönelik ilişkinin izleri, bu bölüm altında incelenen filmler ile görülebilmektedir. (Masiero, 2006, S.14)

"Çevre ve Mekan Psikolojisi Bağlamındaki Filmler" başlı̆̆1 adı altında, sinema ve mimarlığın vazgeçilmezi olan mekan mefhumunu, kendine sorun edinen filmler ele alınmıştır. Bu filmlerdeki mekanlar; insan bedeni “Johnny Silahını Kaptı", bir tür heterotopyaya dönüşen platform "Dogville", konuyu tekrarlayacak şekilde betimlenmiş oteller "Barton Fink, Cinnet" ya da insani kurguyu barındırmayan doğa "Kış Uykusu" vb. olmak üzere farklı ölçek ve bağlamlarda kurulmuştur. Seçilen filmlerdeki mekan tahayyülü çeşitliliği, okuyucunun düşsel dünyası için zengin bir kaynak oluşturmaktadır ve gündelik hayatta karşılaştığımız, bilindik mekan imajını yerinden etmektedir. İki sanat dalında da önemli bir yer teşkil eden mekan, bu bölüm altında incelenen filmler ile okuyucunun zihnindeki tanımlamaların genişlemesine katkı sağlamaktadır.

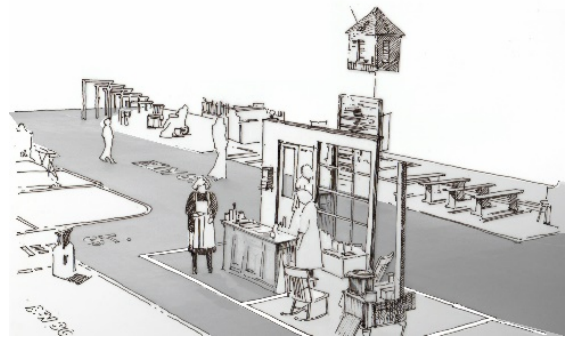

Şekil 2. Çevre ve Mekan Psikolojisi Bağlamındaki Filmler Bölümü İllüstrasyonu (Akarsu, H. T. ve Erdoğan, N. ve Özbursalı. T. (Der.). (2020). Sinemada Mimarlı. İstanbul, Yem Yayın.)

"Mimarlık Sosyolojine Dair Filmler" başlığı adı altında, bir takım toplumsal ve iktisadi değişim ve dönüşümlerin izlerini, insan ilişkileri ve mekan kurguları üzerinden ele alan filmler incelenmiştir. Söz gelimi, "Gurbet Kuşları" filmi ile göç olgusu, "Amerikan Güzeli” filmi ile kapitalizmin yarattığ 
fantazmagoryalar ve "Modern Zamanlar" filmiyle ise modernizmin gündelik yaşamdaki izleri hicivli bir şekilde ele alınmıştır. Daha başka filmlerin de incelendiği bu bölüm ile birlikte hayatımızda başat rol oynayan iktidar erkinin yansımalarının peşine düşülmüştür. Bu türden bir yaklaşım, mimarlığın sadece inşai faaliyetlerden ibaret olduğu düşüncesinin ne kadar yanıltıcı ve eksik kalacağını gözler önüne sermektedir. Mimarlık pratiği bulunduğu konumu itibariyle hem edimsel bir niteliğe sahipken hem de provokatif bir eyleyiciliğe sahiptir. Yaratılan mekanlar neden ve sonuç olma halini eşzamanlı bir şekilde bünyesinde barındırmaktadır. Dolayısıyla bu bölüm ile birlikte mimarlığın neden-sonuç ilişkileri sinematografik betimleme aracilığıyla değerlendirilmektedir.

"Bilimkurgu ve Distopyalar" başlığı adı altında, gelecek tahayyülü üzerine kurulu filmler ele alınmaktadır. Diğer bölümlere kıyasla en fazla film bu başlık altında bulunmaktadır. Bunun sebebi bilimkurgu filmlerinin daha fazla olmasından değil bilimkurgu sinemasının diğer tür sinema filmlerine göre daha çok tahayyüle dayalı olmasındandır. Bu yüzden bilimkurgu sinemasını belli bir tanıma sığdırmak zordur. Bilimkurgu sineması bilindik olanın veya olagelenin peşine takılmaktan daha çok kurduğu dünyayı olağanlaştırmayı hedefler. Bu dünya kimi zaman ütopik kurgulanmıştır kimi zaman ise distopik kurgulanmıştır. Bu türden bir ayrımın oluşmasını ise bilimsel gelişmelere olan yaklaşım farklılıkları belirlemektedir. "Metropolis"(1927) filminden başlayıp "Bulut Atlası"(2012) filmine kadar olan aralıktan seçilen filmler bu bölümde ele alınmıştır. İçerisinde "Başlangıç", "Matrix" ve "BladeRunner" gibi büyük ses getiren filmlerin de bulunduğu bu bölümle birlikte okuyucu geçmişin gözüyle bugünü ve bugünün gözüyle geleceği deneyimleme imkanı sağlamaktadır. Bu çok zamanlı deneyimi seçilen filmlerde bazen mekan kurguları üzerinden bazen ise karakter ilişkileri üzerinden yaşamaktayız. Her ikisinde de bilimkurgu sineması kendine özgü bir bakış açısı oluşturmayı başarmakta ve izleyiciyi bu bakışa ikna etme yetkinliğine ulaşmaktadır. 


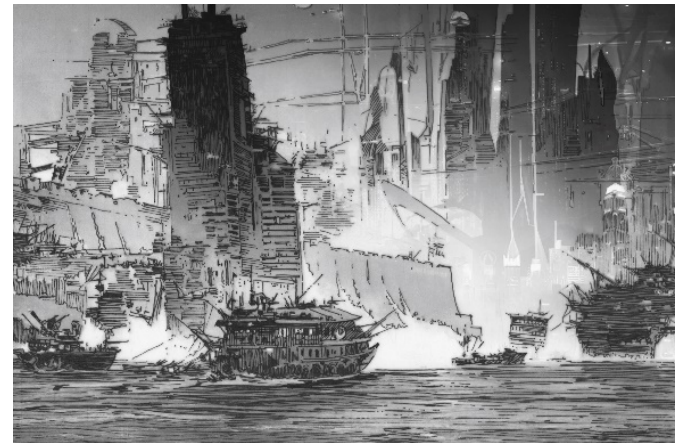

Şekil 3.Bilimkurgu ve Distopyalar Bölümü İllüstrasyonu

(Kaynak: Akarsu, H. T. ve Erdoğan, N. ve Özbursalı. T. (Der.). (2020). Sinemada Mimarlı. İstanbul, Yem Yayın.)

"Kent Kimliğine Dair Filmler" başlığı adı altında incelenen filmler aracılığ1 ile insan gözünün deneyimlemekte zorlanacağı noktalardan kente bakma şansı buluruz. Hemen hemen her gün insan ölçeğinde bir bakışla gezinip durduğumuz kentlerin, başka bir veçhesini görmeye başlarız. Bu bakış ölçülemeyen soyut değerleri ortaya çıardığı gibi kimi zaman ise göz ardı edilen sorunların büyüklüğünü tüm yönüyle ortaya çıkarmaktadır. Söz gelimi "Gün Doğmadan" filminde Viyana ele alınırken "Roma" filminde ise Fellini'nin gözünden Roma'yı görmekteyizdir. Gün Doğmadan filminde kent, filmin konusu gereği turistik bir betimlemeyle kurgulanırken Roma filminde ise kent yönetmenin kendine dert edindiği insan ruhunun kestirilemezliğine alet edilir. Böylece mimari yapıların kent yaşamı içinde farklı kesitlerine şahitlik ederiz, kentin soluğunu duymaya başlarız. Bu yönüyle sinema kentin yaşam kesitini sunan yegâne sanatlardan birisidir.

"Politik Mimari Bağlamındaki Filmler" başlığı adı altında incelenen filmlerde ideolojilerin insan ilişkileri ve dolayısıyla mekan üzerinde ne türden bir dönüşüme yol açabileceğini görmekteyiz. "Doktor Jivago" filmi 1917'de yaşanan Sovyet Devrimini nirengi noktası alarak öncesi ve sonrasında yaşanan gelişmeler üzerinden sosyalizm eleştirisi yapmaktadır. Bu kurguyu yaparken de konuttan balo salonlarına, geniş cadde ve sokaklardan meydanlara değin mimari mekanlardan oldukça faydalanmaktadır. Devrim izlerini bu mekanlara işlemektedir. Yine benzer bir şekilde "Konformist" filminde de faşizm ve kişilik arayışını izleri, kamera açıları ve mekan kurgusu aracıllğıyla desteklenmektedir. Bu bölümdeki diğer filmlere de bakıldığında genel olarak düşünsel olan ile görsel olanın, zihinde oluşturulan imgeler aracılığ 1 ile ilişkilendirildiğini görmekteyiz. 
"Zaman ve Mekan Bağlamına Dair Filmler" başlığı adı altında incelenen filmler; zaman, mekan ve ilişkisini sinematografi aracılığıyla yeniden kurarak izleyiciyi sorgulamaya iten bir kurguya sahiptirler. Bu sorgulamayı en kuvvetli yaptıran filmlerden birisi hiç kuşkusuz "Truman Show" dur. Filmin başrolü hariç hemen hemen her şeyin kar amacı güden bir kurgu olması gerçeğinin etkisi film bitse dahi uzunca bir süre geçmemektedir. Bu etkinin böyle bir sürdürülebilirliğe sahip olması her ne kadar izleyicinin ruhsal dünyası ile ilişkilendirilebilse de filmde kullanılan zaman ve mekan tasvirlerinin etkisi azımsanamayacak kadar fazladır. Öyle ki bu tasvirlerin çoğu gündelik yaşantımızın birer kopyası olma niteliğindedir. Yine bu bölümde incelenen "Tarkovski Sineması" ya da "Göl Evi" vb. filmler ile bu sorgulamalar yönetmenlerin gözünden ele alınmaktadır. Böylesine bir sorgulama içinde olan filmler izleyicinin varoluşsal sancılarını artırmakta, kendisi ve çevresiyle olan ilişkisini sorgulamaya itmektedir. Bu bağlamdan bakıldığında mekan yaratma sanatı olarak tanımlayabileceğimiz mimarlığın etki gücü incelenen filmler aracılığıyla vurgulanmaktadır.

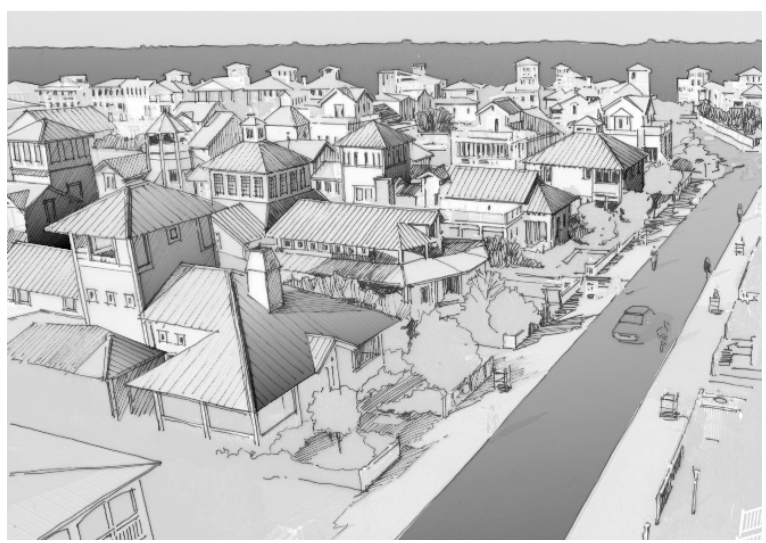

Şekil 4.Zaman ve Mekan Bağlamına Dair Filmler Bölümü İllüstrasyonu (Kaynak: Akarsu, H. T. ve Erdoğan, N. ve Özbursalı. T. (Der.). (2020). Sinemada Mimarlı. İstanbul, Yem Yayın.)

"Mimari ve Tarih Bağlamında Filmler" başlığı adı altında incelenen filmler epik nitelikte, öğretici yanı ağır basan, kültür, din veya felsefenin geçmiş dönem izlerini süren filmlerdir. "Ben-Hur" filmi ile Roma imparatorluğu, Yahudi tarihi ve Hristiyanlık'ın ortaya çıkışı gibi konular ele alınırken Umberto Eco'nun aynı adlı romanından uyarlanan "Gülün Adı" filmi ise 14. yüzyıl Avrupa'sında geçen iktidar erki ile papalık kurumu arasındaki otorite savaşını konu edinmektedir. Tarihin sinema aracılığıyla günümüzde 
yeniden canlandırılması yazılı kaynaklara kıyasla o dönemin içinde bulunduğu ortamı daha keskin bir şekilde ortaya koymaktadır. Bu ortamın oluşturulmasında mimari öğelerin katkısı doğrudandır çünkü tarihi yapıların zamanla simgesel bir değeri oluşmaktadır. Ayrıca her ne kadar "-mış" gibi yapılsa bile böylesi bir canlandırma dönemin ruhunun kavranmasını da kolaylaştırmaktadır. Canlandırılan dönem yapılarının nasıl kullanıldığı hakkında fikir yürütme olanağımızı arttırmaktadır.

"Ekolojik Filmler" ve "Fantaziler" kitabın son iki bölümünü oluşturmaktadır. Ekolojik filmler başlı̆̆ altında doğa-insan-kent ilişkilerini ve küreselleşmenin bu ilişkiler üzerindeki tahakkümünü konu edinen belgesel ve filmler incelenmektedir. Bunların içerisinde "Koyaanisqatsi" adlı deneysel belgesel senaryosuz, oyuncusuz ve diyalogsuz olmasiyla ayrı bir etki uyandırmaktadır. Bu bölümdeki film ve belgeseller izleyicide, insanın ve insanlığın sonucu olan kentlerin evrendeki yerinin altını çizmekte ve düşündürtmektedir. Fantaziler başlığı altında ise fantastik kişileri, mekanları ve olayları konu edinen filmler incelenmektedir. "Alice Harikalar Diyarında", "Yüzüklerin Efendisi" ve "Charlie'nin Çikolata Fabrikası" vb. filmler gerçek dışı karakterleri, ilişkileri ve onlara göre uyarlanmış çevreleri ile alıştığımız standardizasyonu yıkan betimlemeler sunmaktadırlar. Bu açıdan bu türden filmler de izleyicinin hayal dünyasını zenginleştirme noktasında katkı sağlamaktadır.

Pallasma mimarlı̆̆ın, sınırsız mekanı ve sonsuz zamanı evcilleştirerek insana sunan bir işlevi olduğundan bahsetmektedir. (Pallasmaa, 2016, s.22) Sinema da bu bağlamda düşünüldüğünde insanın algı dünyası üzerinde benzer işlevlere sahiptir. Bu yüzden mimariyle olan bitimsiz ilişkisi yadsınamayacak kadar güçlüdür. Yukarıda incelenen bölüm başlıklarından da anlaşılacağı üzere, kitap geniş film seçkisi ve yoğun içeriği ile bu ilişkiyi farklı açılardan okuyucuya sunmaktadır. Fakat böylesi bir kurgunun seçilmesinin nedeni; doğanın ürpertici tahribi sonucu ortaya çıkan ekolojik felaketler, rant hırsı peşinde sürüklenen insanlık ve gün geçtikçe şiddetini artıran tahakküm düzeni gibi günümüz sorunlarına çözüm getirme yolunda önemli bir adım sayılabilecek olan mimarlık stüdyolarının kültürel, eleştirel ve estetik açıdan birikimine katkı sağlayan bir ekol oluşturma gayesindendir. (Akarsu, Erdoğan ve Özbursalı, 2020, s.10-11) Günümüzde mimarlık stüdyolarının bazen düşünsel bazen ise uygulamalı olarak, bir tür piyasaya hazırlık doğrultusunda oluşturulan içeriğinin ne türden kötü tecrübelere yol açtığ gözükmektedir. Bu türden kötü tecrübelerin önüne geçmeyi hedefleyen kitap, başta mimarlar olmak üzere okuyucularının eleştirel kimli- 
ğini güçlendirmek, yaratıcı faaliyetlerini beslemek ve sanatsal kaygısını arttırmak için odağına sinemayı almaktadır. Sinemanın zamanı ve mekanı yeniden üreterek oluşturduğu kurgusu bir çok açıdan zengin bir deneyim sunma imkanı barındırmaktadır. Çoğu kez oluşturduğumuz dünya içinde sınırlı kalan bizleri bazen gözlemci konumuna yerleştirmekte bazen ise yeni dünyaların içine bırakarak bakış açımızı genişletmektedir. Bu deneyim faklı disiplinlerdeki insanların görüşleriyle de birleşince daha da genişlemektedir.

Sonuç olarak; kitabın, zaman-mekan ilişkisinden mimarlık pratiğine, günümüz kentleri ve sorunlarından ideolojik algılara varıncaya kadar genişletilen bu yoğun içeriği, bir çırpıda okunmasına izin vermeyen niteliksel bir ağırlığa sahiptir fakat çok sesli yapısı, özenle seçilmiş kült filmleri ve büyük çaba gerektiren editoryal kurgusu ile günümüz sorunlarında başat bir rol oynayan, mimarlık disiplinini kendi alanına hapseden yaklaşımlara karşı, güçlü bir argüman oluşturmaktadır.

\section{Kaynakça}

Akarsu, H. T. ve Erdoğan, N. ve Özbursalı. T. (Der.). (2020). Sinemada Mimarlik. İstanbul, Yem Yayın.

Masiero, R. (2006). Mimaride Estetik. (F. Genç, Çev.). Ankara, Dost Kitabevi Yayınları. (Orijinal eserin yayın tarihi 1999).

Pallasmaa, J. (2016). Tenin Gözleri. (A. U. Kılıç, Çev.). İstanbul, Yem Yayın. (Orijinal eserin yayın tarihi 2005).

Picon, A. (2019). Mimarlı̆̆ı Maddiliği. (A. Tümertekin, Çev.). İstanbul, Janus Yayıncllk. (Orijinal eserin yayın tarihi 2018). 